Original Research Article

\title{
A Retrospective study of analysis of reasons for discard of blood and blood components
}

\author{
Mamatha S.V. ${ }^{1}$, Chaithra H. ${ }^{2}$, Susmitha N.S. ${ }^{3}$, Anand R. ${ }^{4}$ \\ ${ }^{1}$ Dr. Mamatha, SV, Associate Professor, ${ }^{2}$ Dr. Chaithra H, Assistant Professor, ${ }^{3}$ Dr. Susmitha NS, Assistant Professor, \\ ${ }^{4}$ Dr. Rajatha Anand, Assistant Professor, all authors are affiliated with Department of Pathology, Sri Siddhartha Medical \\ College, Tumkur, Karnataka 527107, India.
}

Corresponding Author: Dr. Mamatha SV, Associate Professor, Department of Pathology, Sri Siddhartha Medical College, Tumkur. Emailed: drmamathasv@gmail.com

\begin{abstract}
Introduction: Blood transfusion is an essential element in modern health care. Transfusion of blood and blood components has become an integral part of patient management in modern medicine. Human blood till date has no substitute. Demand of blood and its components always outpace its supply. This emphasizes the need for proper utilization of blood and its components with preferably "NO" or minimal wastage. Materials and methods: A Retrospective study of analysis was carried out at Sri Siddhartha Medical College Hospital Blood bank from $1^{\text {st }}$ January 2017 to December 31 ${ }^{\text {st }}$ 2017. Results: Out of 1806 whole blood bags, 371 (5.21\%) were discarded. 137 (36.9\%) units were discarded because of transfusion transmitted infections (TTIs). Out of 11809 components prepared, 1027 (8.6\%) were discarded. Most common component discarded was platelet (40.7\%) and reason for discard was date of expiry due to non-utilization. Conclusion: Blood being irreplaceable source, discard rate can be reduced by proper counseling of blood donors and adhering to strict donor deferral criteria. Discard rate of platelet concentrate can be minimized by preparing platelet concentrate on request and also by using modern technique like Apheresis.
\end{abstract}

Keywords: Discard rate, Packed red cells (PRC), Fresh Frozen plasma (FFP), Platelet concentrate (PC), Transfusion transmitted infections (TTIs), Hepatitis C virus (HCV)

\section{Introduction}

Blood transfusion is an essential element in modern health care [1]. Transfusion of blood and blood components has become an integral part of patient management in modern medicine [2]. The aim of blood transfusion service should be to provide effective blood and blood products, which are safe as possible and adequate to meet the patients need [3]. Requirement of blood is there in every two second [4]. One third of all patients admitted to intensive care units (ICUs) in the developed world receive a blood transfusion [5]. Human blood till date has no substitute. Demand of blood and its components always outpace its supply. This emphasizes the need for proper utilization of blood and its components with preferably "NO" or minimal wastage [5]. The aim of present study is to analyze the reason for discarding of whole blood and blood components so that they can be used judiciously and to minimize the number of discarded blood and blood components.

Manuscript received: $26^{\text {th }}$ June 2018

Reviewed: $4^{\text {th }}$ July 2018

Author Corrected: $12^{\text {th }}$ July 2018

Accepted for Publication: $17^{\text {th }}$ July 2018

\section{Materials and methods}

A Retrospective study of analysis was carried out at Sri Siddhartha Medical College Hospital Blood bank from $1^{\text {st }}$ January 2017 to December $31^{\text {st }} 2017$. Blood donations were taken from voluntary and replacement/ family donors as well as in blood donation camps according to selection criteria defined by WHO [7].

Blood components such as packed red cells (PRC), fresh frozen plasma (FFP) and platelet concentrate (PC) were prepared from $450 \mathrm{ml}$ blood bags under all aseptic conditions according to Food and Drug Administration (FDA) guidelines as per demand and manpower available in the blood bank [7]. The blood bags were discarded according to standard operating procedures laid down by National AIDS control organization (NACO)[8]. Blood bags included in the present study were screened for transfusion transmissible infections (TTIs). Blood bags tested positive for infections, blood bags in which inappropriate amount of blood was collected, blood bags with hemolysed blood and blood bags damaged during centrifugation were discarded. 


\section{Original Research Article}

\section{Results}

Among 7109 total donors in present study $(74.73 \%)$ were voluntary donors and $(25.26 \%)$ were replacement donors.

Table 1 gives the source of blood bags as per type of donors

Table-1: source of blood bags as per type of donors.

\begin{tabular}{|c|c|c|}
\hline Type of donors & Total & Percentage (\%) \\
\hline Voluntary & 5313 & 74.73 \\
\hline Replacement & 1796 & 25.27 \\
\hline Total & $\mathbf{7 1 0 9}$ & $\mathbf{1 0 0}$ \\
\hline
\end{tabular}

Out of total 7109 blood bags collected during the study period, 1806 units were collected in a $350 \mathrm{ml}$ blood bags and $371(5.21 \%)$ bags were discarded. Amongst the 371 whole blood bags discarded, testing positive for TTIs was the most common cause $(36.9 \%)$ followed by expiry of date due to non utilization $(30.1 \%)$. Other reasons for discarding of whole blood bags were less volume collected in $(28.8 \%)$ and hemolysis $(4 \%)$. Table 2 gives analysis for reason of discarded whole blood bags.

Table-2: Analysis of reason for discard of whole blood bags.

\begin{tabular}{|c|c|c|}
\hline Reason for discarding & Total number & Percentage (\%) \\
\hline Positive for TTIs & 137 & 36.9 \\
\hline Date expired & 112 & 30.1 \\
\hline Less volume & 107 & 28.8 \\
\hline Hemolysis & 15 & 4.0 \\
\hline
\end{tabular}

Hepatitis B infection was the most common reason for discarding whole blood accounting for $64.9 \%$ cases, followed by syphilis in $16.7 \%$, HCV $13.1 \%$ and HIV in 5.1\%. Table 3 gives analysis of reason for discarding whole blood bags testing positive for transfusion transmissible infections (TTIs).

Table-3: Analysisof reason for discarded whole blood bags tested for TTIs

\begin{tabular}{|c|c|c|}
\hline Transfusion transmitted infection (TTI) & Total number & Percentage (\%) \\
\hline Hepatitis B & 89 & 64.9 \\
\hline Syphilis & 23 & 16.7 \\
\hline HCV & 18 & 5.1 \\
\hline HIV & 07 & - \\
\hline Malaria & - & 13.1 \\
\hline
\end{tabular}

A total of $1027(8.69 \%)$ blood components were discarded against 11809 blood components prepared during present study period. Out of 1027, most common component discarded was plateletand discard rate was $40.7 \%$, followed by fresh frozen plasma (6.6\%) and packed red cells (3.2\%). Table 4 gives analysis of discarded units of blood components against total prepared components

Table-4: Analysis of discarded units of blood components against total prepared components.

\begin{tabular}{|c|c|c|c|}
\hline Component & $\begin{array}{c}\text { No of components } \\
\text { prepared }\end{array}$ & No of units discarded & $\begin{array}{c}\text { Discarded rate } \\
\text { Percentage (\%) }\end{array}$ \\
\hline Packed red cells & 5287 & 170 & 3.21 \\
\hline Fresh frozen plasma & 5287 & 354 & 6.69 \\
\hline Platelets & 1235 & 503 & 40.7 \\
\hline Total & $\mathbf{1 1 8 0 9}$ & $\mathbf{1 0 2 7}$ & $\mathbf{8 . 6 9}$ \\
\hline
\end{tabular}




\section{Original Research Article}

Most common reason for discard of blood components was expiry due to non utilizationand testing positive for TTIs. Table 5 gives analysis of reason for discarding blood components

Table-5: Analysis of reason for discarding blood components

\begin{tabular}{|c|c|c|c|}
\hline Blood components & Date Expired & Leakage & Positive for TTIs \\
\hline Packed red cells & 21 & - & 149 \\
\hline Fresh frozen plasma & 198 & 07 & 149 \\
\hline Platelets & 487 & - & 16 \\
\hline Total (1027) & $\mathbf{7 0 6}$ & $\mathbf{0 7}$ & $\mathbf{3 1 4}$ \\
\hline
\end{tabular}

\section{Discussion}

The need for blood and blood components is presently increasing due to improved and accurate diagnosis of complex diseases requiring transfusion [2].

Proper blood management at blood bank will reduce unnecessary wastage of blood and blood components. A self audit of whole blood and blood components discarded over a period of time gives an idea about various reasons of discard [2].

Whole blood- In present study discard rate for whole blood was $(5.21 \%)$, which is slightly higher compared to Sharma etal [6](4.46\%) and BobdeV et al [9](6.63\%). In a study by Suresh et al [10]5.7\% whole blood bags were discarded.

Most common reason for discard of whole blood in present study was TTI positive status of donors accounting for $(36.9 \%)$ followed by date of expiry in $30.1 \%$. In a study by Kumar et al $(74.30 \%)$ of whole blood bags were discarded for TTIs followed by date of expiry in $11.84 \%$ [11].

In present study, Hepatitis B infection was the most common reason for discardin $64.9 \%$ as comparable to study by Suresh et alin which study, $64.4 \%$ units were discarded for Hepatitis B infection [10].

Other reasons for discard of whole blood included less quantity collected $28.8 \%$ and hemolysis in $4 \%$.Reason for less quantity collected was to due donor reaction such as vomiting and fainting during donation.

Blood components- A total of 1207 (8.69\%) blood components were discarded against 11809 components prepared in present study. In a study by Suresh et al 24847 blood components prepared and $7 \%$ of units were discarded. Discard rate was slightly lower compared to present study [10]. Reasons for discard of blood components in present study were date expired (67\%),testing positive for TTIs (30.5\%), less volume collected due to donor adverse reaction in $(1.3 \%)$ and leakage of blood bags damaged during component separation in $(0.8 \%)$

Out of 314 (67.1\%) tested positive for TTIs, Hepatitis B infection was positivein $70.5 \%$ units, followed by Hepatitis C virus infection (14.8\%) syphilis (9.1\%) and HIV (4.7\%). In a study conducted by Thakare MM et al[12] Hepatitis B (49.82\%) was most common TTI followed by HIV (10\%) and HCV (8.97\%).

The most common blood components discarded were platelets $(40.7 \%)$ followed by fresh frozen plasma $(6.69 \%)$ and packed red cells $(3.21 \%)$ as shown in table no 4.

Discard rate for platelets in present study was slightly lower $(40.7 \%)$ ascompared to studies by Sharma et al [6] (43.6\%). In a study by Ghaflez M Bet al [13] discard rate for platelets was high $(61.11 \%)$. Table 5 gives analysis of reasons for discarding blood components.

Most common reason for discard of platelets was date of expiry due to non utilization. Similar findings were observed in studies conducted by Kumar etal [11] and Deb et al [14]. High discard rate of platelets was due to short shelf life offive days.

So their chance of expiry due to non utilization was highest among blood components. To minimize high discard, platelets should be prepared on request and using modern techniques like apheresis [15].

Discard rate for fresh frozen plasma (FFP) was $6.69 \%$ in present study. In a study by Sharma et al [6] discard rate of FFP was $6.2 \%$ and slightly higher discard rate of (7.6\%) was reported by Bobde $\mathrm{V}$ et al [9].

Most common reason for discard of FFP was testing positive for TTI followed by non-utilization after issue and leakage. Reason for non-utilization was excess of 


\section{Original Research Article}

FFP units requested against requirement. Leakage of FFP bags can be minimized by putting FFP bags in a cardboard polystyrene protective container that minimizes the risk of breakage of product during storage, handling and transportation [2].

In present study, discard rate for packed red cells(PRC) was $3.21 \%$ as comparable to studies by Sharma et al[6] $(3.2 \%)$ and Suresh B et al[10](3.3\%).

Discard rate for PRC was higher $(6.76 \%)$ in a study conducted by Patil P et al [15] and most common reason for discard of PRC was TTI positive status of donors followed by date of expiry.

Proper donor screening and strict adherence to donor selection guidelines would decrease the collection of such units from donors, thereby avoiding discard of such units [15].

Wastage of blood components can be minimized by proper handling of blood bags, adhering to stringent storage conditions of refrigerators in blood bank to prevent hemolysis and bacterial contamination [15].

\section{Conclusion}

Proper utilization of blood and blood components with minimal wastage is of utmost importance in saving life. Blood being irreplaceable source, discard rate can be reduced by proper counseling of blood donors and adhering to strict donor deferral criteria. In present study, platelet concentrate was the most common blood component discarded and discard rate can be minimized by preparing platelet concentrate on request and also by using modern technique of platelet preparation by apheresis.

During manuscript preparation other authors contributed to preparation of manuscript by helping in analysis of data and providing relevant articles.

What this study add to existing knowledge? In present study of analysis for reason of discard of blood and blood components, discard rate of blood and components can be reduced by collection of blood from voluntary blood donors and preparation of platelets by apheresis technique.

Sri Siddhartha Medical College is located in a rural area in Tumkur district of Karnataka and we have to motivate and educate people to donate blood voluntarily.

Funding: Nil, Conflict of interest: None initiated Permission from IRB: Yes

\section{References}

1. Mahapatra S, Sahoo BB, Ray GK, Mishra D, Panigrahi R, Parida P. Discard of blood and blood components with study of causes $-\mathrm{A}$ good manufacture practice. Wjpmr.2017,3(2),172-175.

2. World Health Organization. Quality systems for blood safety: introductory module guidelines and principles for safe blood transfusion practice. Geneva: World Health Organization. 2002;65-75.

3. World Health Organization. Developing a National Policy and Guidelines on the clinical use of blood. Recommendations .Geneva. WHO 2009.

4. Blood transfusion safety. Available at URL:http// www.who.int/bloodsafety/in/bloodtransfusion_safety/en /blood_Transfusion Safety. pdf. Accessed on June 16, 2015.

5. Saxena S, Weiner JM, Rabinowitz A, et al. Transfusion practice in medical patients. Arch Intern Med. 1993 Nov 22;153(22):2575-80

6. Sharma N, Kaushik S, Kumar R, AzadS, Acharya A, Kudesia S.Causes of wastage of blood and blood components: A retrospective analysis. IOSR-JDMS. 2014; 13(12):59-61

7. Saran RK. Transfusion Medicine Technical Manual. 2nd ed. Drugs Controller General, India. Directorate General of Health Services, Government of India. 2003

8. National AIDS Control Organization. Standards for blood banks and blood transfusion services. New Delhi, Ministry of Health and Family Welfare, Government of India. 2007.

9. Bobde V, Parate S, Kumbhalkar D. Analysis of discard of whole blood and blood components in government hospital blood bank in central India. $\mathrm{J}$ of Evidence Based Med \& Healthcare. 2015;2(9):1215-9.

10. Suresh B, Sreedhar Babu KV, Arun R, Chandramouli P, Jothibai DS. Reasons for discarding whole blood and its components in a tertiary care teaching hospital blood bank in South India. J Clin Sci Res. 2015;4:213-9.

11. Kumar A, Sharma SM, Ingole NS, Gangane N. Analysis of reasons for discarding blood and blood components in a blood bank of tertiary care hospital in central India: a prospective study. Int J Med Public Health 2014;4:72-4. 


\section{Original Research Article}

12. Thakare MM, Dixit JV, Goel NK. Reasons for discarding blood from blood bank of Government Medical College, Aurangabad. Asian J Transfus Sci 2011; 5:59-60.

13. Ghaflez MB, Omeir KH, Far JM, Saki N, Maatoghi TJ, Naderpour M. Study of rate and causes of blood components discard among Ahwaz's hospital. Scientific Journal of Iran Blood Transfus Organ. 2014;11(3):197206.
14. Deb P, Swarup D, Singh MM. Audit of blood requisition. DOI: 10.1016/ S0377- 1237 (01) 800 $87-3$

15. Patil P, Bhake A, Hiwale K. Analysis of discard of whole blood and its components with suggested possible strategies to reduce it. Int J Res Med Sci 2016;4(2):477-81

\section{How to cite this article?}

Mamatha S.V, Chaithra H, Susmitha N.S, Anand R. A Retrospective study of analysis of reasons for discard of blood and blood components. Trop J Path Micro 2018;4(3):276-280.doi:10. 17511/jopm.2018.i3.07 